\title{
Improving Heat Exchange Performance of Massive Concrete Using Annular Finned Cooling Pipes
}

\author{
Lemu Zhou $\mathbb{D}^{1,2}$ Fangyuan Zhou ${ }^{10}{ }^{3}$ and Hanbin Ge ${ }^{1}{ }^{1}$ \\ ${ }^{1}$ Department of Civil Engineering, Meijo University, Nagoya, Japan \\ ${ }^{2}$ Hubei Provincial Road \& Bridge Company, Wuhan, China \\ ${ }^{3}$ School of Civil Engineering and Mechanics, Huazhong University of Science and Technology, Wuhan, China \\ Correspondence should be addressed to Fangyuan Zhou; fangyuanzhou@hust.edu.cn and Hanbin Ge; gehanbin@meijo-u.ac.jp
}

Received 17 February 2021; Revised 26 April 2021; Accepted 5 July 2021; Published 16 July 2021

Academic Editor: Shuaicheng Guo

Copyright (C) 2021 Lemu Zhou et al. This is an open access article distributed under the Creative Commons Attribution License, which permits unrestricted use, distribution, and reproduction in any medium, provided the original work is properly cited.

Cracks will be generated due to high internal temperature of the massive concrete. Postcooling method is widely employed as a standard cooling technique to decrease the temperature of the poured mass concrete. In this paper, an annular finned cooling pipe which can increase the heat transfer area between the flowing water and its surrounding concrete is proposed to enhance the cooling effect of the postcooling method. Analysis of the interior temperature variation and distribution of the concrete block cooled by the annular finned cooling pipe system and the traditional cooling pipe system was conducted through the finite element models. It is found that, for the concrete block using the proposed annular finned cooling pipe system, the peak value of the interior temperature can be further lowered. Compared with the traditional cooling pipe, the highest temperature of concrete with an annular finned cooling pipe appears earlier than that with the traditional cooling pipe.

\section{Introduction}

In the construction of dams and long-span suspension bridges, mass concrete blocks are cast. The released hydration heat of the massive concrete cannot be dissipated quickly because of the poor thermal conductivity of concrete. Therefore, a large temperature difference can be generated between the surface and the core area of the concrete during the early stage of the pouring concrete [1-3]. The large temperature difference may lead to cracks, which may reduce the durability of the massive concrete [4-6]. Therefore, reducing the internal temperature of massive concrete becomes a research hotspot during the past few decades.

An efficiency way named postcooling method is often used to change the internal temperature distribution of the massive concrete structures $[7,8]$. The internal temperature distribution of mass concrete can be changed by the cool water running through pipes. The cooling effect of the postcooling method has been verified during the construction process of Hoover dam in the last century [9]. After that, loads of scholars have emerged in this research area. The content of the research mainly embraces three aspects: theoretical model, numerical simulation, and practical test.

In terms of theoretical model: Zhu and Cai [10] investigated the cooling efficiency of the pipe during the construction of the pouring concrete. A theoretical method was given for analyzing the heat transfer between the concrete and the cooling fluid. Meanwhile, some practical computing methods and relevant charts were presented for the convenience of engineers. Feedback analysis method for calculating the temperature variation in mass concrete structures was presented by Ding and Chen [11]. The method was applied in a dam during its construction period. Zhong et al. [12] put forward a composite element method to improve the computational efficiency in the calculation of temperature distribution in mass concrete with water running in the cooling pipe. The availability of the proposed method was confirmed by finite element method. The theoretical solution of nonmetallic cooling pipe, compared with metallic cooling pipes, was investigated by Chen et al. [13]. Mogharrebi et al. [14] proposed an evaluation of $3 \mathrm{D}$ convective heat exchange characteristics 
of magneto-hydrodynamic nanofluid flow, containing motile oxytactic microorganisms and nanoparticles passing through rotating cones.

In terms of numerical simulation, Kim et al. [15] investigated the hydration heat of the mass concrete embedded with cooling water pipeline by using a finite element program. By comparing to the data measured from the process of the construction of a bridge in Korea, the simulation results obtained through the three-dimensional finite element program showed good agreements. Myers et al. [16] proposed an approximate model for simulating the cooling process of the massive concrete with cooling pipe. An analytical model was also presented for simulating the heat generation process of the concrete. Yang et al. [17] proposed a finite element program for analyzing the thermal distribution of the massive concrete. Through the experimental verification, it is certificated that the numerical model is effective in calculating the temperature distribution of mass concrete. For reflecting the temperature distribution around the cooling pipe, a procedure for a heatfluid coupling model was putted forward by Liu et al. [18]. Hong et al. [19] put forward a numerical simulation algorithm of transient temperature field considering the influence of ambient temperature and cooling pipe size. Rostami et al. [20] numerically simulated the convective heat exchange under the effect of magnetic forces in $\mathrm{Al}_{2} \mathrm{O}_{3}$-rthylene glycol nanofluids in porous media. Boussinesq-Darcy law and thermal nonequilibrium model are adopted. The suspension of phase change material was employed as a new fluid material by Qian and Guo [21] to assess its cooling performance. The simulation results present that the highest temperature of concrete can be significantly decreased by replacing water with suspension of phase change substances.

In terms of practical test, Liu et al. [22] developed a heatfluid coupling way to conduct the heat simulation of a cooling pipe system. Corresponding tests were conducted to certificate the availability of the proposed heat-fluid coupling method. Based on a scaled experimental model, the temperature distribution and temperature time histories for the core area of the concrete were monitored by Huang et al. [23]. The test results show that the pipe cooling system can greatly reduce the temperature rise. Wu et al. [24] investigated the influence of sodium hydroxide on the hydration of low carbon cementing materials. Geng et al. [25] employed the air pipe cooling technique to transform the temperature distribution of concrete walls; an experimental study of a large dimension wall with properly embedded corrugated pipes was conducted. Hong et al. [26] put forward a collocation method using the localized radial basis function to calculate the temperature distribution in concrete structures with cold pipe. Examples including a problem with multicooling water pipes were investigated. From the calculation results, it can be known that the method can be used in the calculation of temperature distribution in mass concrete structures embedded with cooling pipe systems. Hybrid nanofluid flow containing $\mathrm{MoS}_{2}-\mathrm{TiO}_{2}$ hybrid nanoparticles under the effect of the magnetic field in cavity enclosure has been evaluated by Hosseinzadeh et al. [27]. It was found that the position of horizontal ellipse provides better conditions for fluid flow and thermal convection.
It is widely known that the cooling effect of the postcooling method is limited by the superficial area of the traditional cooling pipe system. Therefore, the one-time pouring height of the massive concrete is usually less than $3 \mathrm{~m}$. Thus, a new cooling pipe system which can increase the cooling efficiency of the massive concrete is needed during the construction of the structures. According to the laws of thermodynamics, the heat transfer efficiency can be increased by increasing the heat exchange area. Therefore, an annular finned cooling pipe which can increase the heat transfer area between the flowing water and its surrounding concrete is proposed in the paper to decrease the internal temperature of the concrete block. Internal temperature variation and distribution of the concrete block is calculated to study the cooling influence of the proposed annular finned cooling pipe.

\section{Description and Validation of the Numerical Model}

2.1. Numerical Model and Its Governing Equations. A commercial software Ansys V 17.0 is used to calculate the hydration heat of massive concrete with cooling pipe. The unsteady conductivity is calculated by the finite volume method, and its control formula is as follows:

$$
\rho C_{p}\left(\frac{\partial T}{\partial t}\right)=\nabla k \nabla T+S_{h}
$$

where $\rho, k, T, S_{h}$, and $C_{p}$ are density, thermal conductivity, temperature, hydration heat per unit of volume, and the specific heat, respectively.

The equation used for the whole hydration heat of the used materials is

$$
Q_{c}=\left(k_{1}+k_{2}-1\right) Q_{0}
$$

where $Q_{0}$ is the whole hydration heat of the cement. $k_{1}$ and $k_{2}$ are the hydration heat adjustment coefficients of cement, mixed with slag and fly ash.

The following is the formula of the thermal insulation warming:

$$
\begin{aligned}
T(t) & =\frac{W Q_{c}}{C \rho}\left(1-e^{-m t}\right), \\
W & =\lambda W_{0},
\end{aligned}
$$

where $W$ represents the consumption of P.I Portland cement in per cubic meter of concrete; $t$ is the age of concrete; $W_{0}$ represents the amount of other types of Portland cement and $\lambda$ is the correction coefficient; $C$ stands for the concrete specific heat capacity; $\rho$ is the concrete density; $m$ is the cementitious coefficient related to the properties of cement, and the formula is

$$
m=\left(k_{1}+k_{2}-1\right)(A W+B),
$$

where $A$ and $B$ represent concrete casting temperature correlation coefficients. 
The water flow in the pipeline is simulated through the standard $k-\varepsilon$ model. The rate of dissipation $\varepsilon$ and the turbulence kinetic energy $\varepsilon$ are used in the model as follows:

$$
\begin{aligned}
& \left(\frac{\partial}{\partial t}(\rho k)+\frac{\partial}{\partial x_{i}}\left(\rho k u_{i}\right)\right)=\frac{\partial}{\partial x_{j}}\left[\left(\mu+\frac{\mu_{t}}{\sigma_{k}}\right) \frac{\partial k}{\partial x_{j}}\right]+G_{k}+G_{b}-\rho \varepsilon-Y_{M}+S_{k} \\
& \left(\frac{\partial}{\partial t}(\rho \varepsilon)+\frac{\partial}{\partial x_{i}}\left(\rho \varepsilon u_{i}\right)\right)=\frac{\partial}{\partial x_{j}}\left[\left(\mu+\frac{\mu_{t}}{\sigma_{\varepsilon}}\right) \frac{\partial \varepsilon}{\partial x_{j}}\right]+C_{1 \varepsilon} \frac{\varepsilon}{k}\left(G_{k}+C_{3 \varepsilon} G_{b}\right)-C_{2 \varepsilon} \rho \frac{\varepsilon^{2}}{k}+S_{\varepsilon} .
\end{aligned}
$$

Here, $C_{1 \varepsilon}, C_{2 \varepsilon}$, and $C_{3 \varepsilon}$ are constants; $G_{b}$ stands for the turbulence kinetic energy created by buoyancy; $Y_{M}$ stands for the contribution of fluctuating dilatation to the total dissipation rate in compressible turbulence. $\sigma_{k}$ and $\sigma_{\varepsilon}$ are the number of turbulent planters of $k$ and $\varepsilon$, respectively. $G_{k}$ represents the turbulence kinetic energy due to the average velocity gradient; and $S_{k}$ and $S_{v}$ are user-defined sources.

2.2. Validation of the Numerical Model. For verifying the correctness of the numerical model, as shown in Figure 1, we compare the interior temperature of cylindrical concrete obtained from the numerical model ground on the control formula described in Section 2.1 with the theoretical value. The cylindrical concrete has a radius of $0.4225 \mathrm{~m}$ and a length of $2.0 \mathrm{~m}$. Cooling water flows through a cylindrical axial pipe. The outer radius of the tube is $0.008 \mathrm{~m}$, and the inner radius is $0.007 \mathrm{~m}$. The concrete pouring temperature is $273 \mathrm{~K}$, and the water inlet temperature is $273 \mathrm{~K}$. P.O 42.5 Portland cement with hydration heat as Figure 2 shows is employed. The proportion of the concrete is depicted in Table 1. On the basis of the standard for construction of mass concrete of China MOHURD [28], the parameters which are needed to identify equation (3) are listed in Table 2.
Combining Figure 2 and Tables 1 and 2, the thermal insulation warming of concrete can be expressed as

$$
T(t)=32.717\left(1-e^{-0.72 t}\right) .
$$

A theoretical solution which was proposed by Zhu $[29,30]$ is employed here to verify the accuracy of the numerical model. For a steel cooling pipe with outer radius $c$ and inner radius $r_{0}$ embedded in a cylindrical concrete (in Figure 1(b)), the heat conduction equation in the cylindrical concrete can be shown as

$$
\frac{\partial T}{\partial \tau}=a\left(\frac{\partial^{2} T}{\partial r^{2}}+\frac{1}{r} \frac{\partial T}{\partial r}\right)+\left(\frac{W Q_{c}}{C \rho}\right) m e^{-m \tau} .
$$

The boundary conditions of the cylindrical concrete are

$$
\text { when } \tau=0, c \leq r \leq b, T(r, 0)=273 \text {, }
$$

when $\tau>0, r=c, T(c, 0)=273$,

$$
\text { when } \tau>0, r=b, \frac{\partial T}{\partial r} \text {. }
$$

The solution of equation (9) can be obtained by the Laplace transformation method, and it can be expressed as

$$
\begin{aligned}
T= & \frac{W Q_{c}}{C \rho} e^{-(b \sqrt{m / a})^{2} a t / b^{2}}\left[\frac{Y_{1}(b \sqrt{m / a}) J_{0}(r \sqrt{m / a})-J_{1} \sqrt{m / a} Y_{0}(r \sqrt{m / a})}{Y_{1}(b \sqrt{m / a}) J_{0}(c \sqrt{m / a})-J_{1}(b \sqrt{m / a}) Y_{0}(c \sqrt{m / a})}-1\right] \\
& +2 \frac{W Q_{c}}{C \rho} \sum_{n=1}^{\infty} \frac{e^{-\alpha 2 / n b^{2} a t / b^{2} a}}{\left[1-\left(\alpha_{n}^{2} b^{2} /(b \sqrt{m / a})^{2}\right)\right] \alpha_{n} b} \frac{Y_{0}\left(\alpha_{n} r\right) J_{1}\left(\alpha_{n} b\right)-Y_{1}\left(\alpha_{n} b\right) J_{0}\left(\alpha_{n} r\right)}{R\left(\alpha_{n} b\right)}, \\
R\left(\alpha_{n} b\right)= & \frac{c}{b}\left[J_{1}\left(\alpha_{n} b\right) Y_{1}\left(\alpha_{n} c\right)-J_{1}\left(\alpha_{n} c\right) Y_{1}\left(\alpha_{n} b\right)\right]+\left[J_{0}\left(\alpha_{n} c\right) Y_{0}\left(\alpha_{n} b\right)-J_{0}\left(\alpha_{n} b\right) Y_{0}\left(\alpha_{n} c\right)\right],
\end{aligned}
$$

where $\alpha_{n} b$ is the root of the following equation:

$$
J_{1}\left(\alpha_{n} b\right) Y_{0}\left(\alpha_{n} c\right)-J_{0}\left(\alpha_{n} c\right) Y_{1}\left(\alpha_{n} b\right)=0,
$$

where $Y_{0}$ and $Y_{1}$ are the zero and first order of Bessel functions of second kind, respectively, and $J_{0}$ and $J_{1}$ are the zero and first order of Bessel functions of first kind, respectively. 


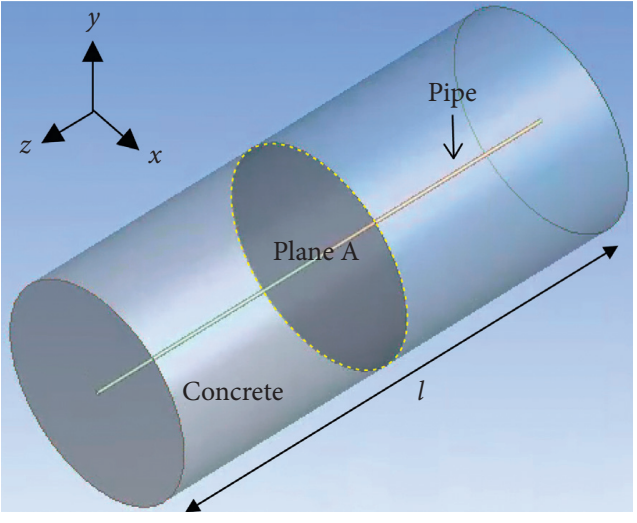

(a)

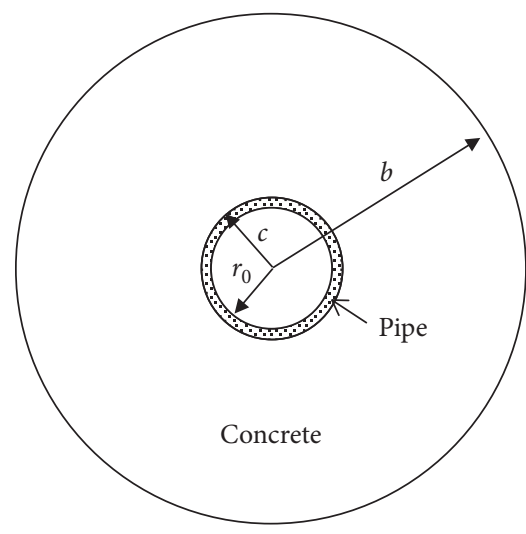

(b)

FIgURE 1: Cylindrical concrete with cooling water pipe: (a) three-dimensional sketch; (b) $x y$ cross section.

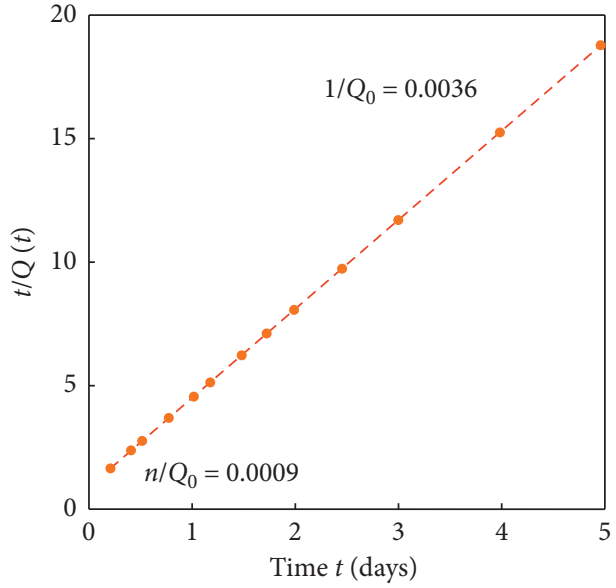

(a)

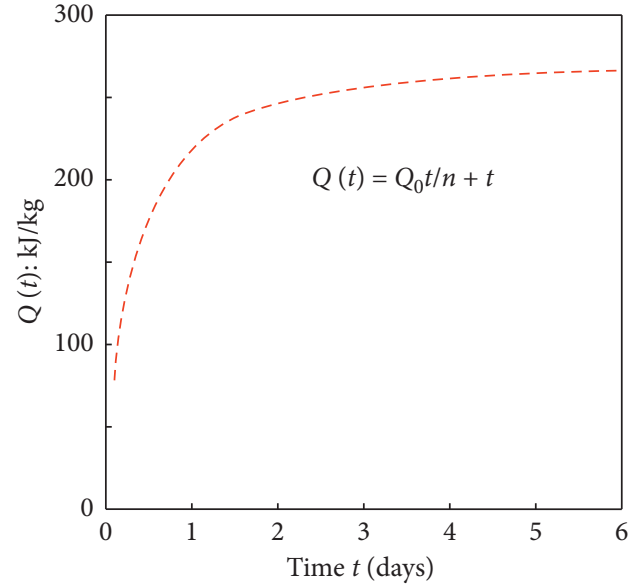

(b)

Figure 2: The hydration heat of cement in different ages.

TABLE 1: The proportion of the concrete $\left(\mathrm{kg} / \mathrm{m}^{3}\right)$.

\begin{tabular}{lccccc}
\hline Cement & Water & Fly ash & Sand & Aggregate & Water reducer \\
\hline 350 & 50 & 727 & 1091 & 4.8 & 165 \\
\hline
\end{tabular}

TABLE 2: Parameters to identify the heat hydration of the concrete.

\begin{tabular}{lccccc}
\hline$\lambda$ & $k_{1}$ & $k_{2}$ & $A$ & $B$ \\
\hline 0.88 & 0.956 & 1 & 0.0023 & 0.045 \\
\hline
\end{tabular}

Through equation (11), the mean temperature of plane A in Figure 1(a) can be calculated by

$$
\begin{aligned}
T_{m}= & \frac{W Q_{c}}{C \rho} e^{-(b \sqrt{m / a})^{2} a t / b^{2}}\left[\frac{2 b c}{\left(b^{2}-c^{2}\right) b \sqrt{m / a}} \frac{J_{1}(b \sqrt{m / a}) Y_{1}(c \sqrt{m / a})-J_{1}(c \sqrt{m / a}) Y_{1}(b \sqrt{m / a})}{J_{0}(c \sqrt{m / a}) Y_{1}(b \sqrt{m / a})-J_{1}(b \sqrt{m / a}) Y_{0}(c \sqrt{m / a})}-1\right] \\
& +\frac{4 b c}{b^{2}-c^{2}} \frac{W Q_{c}}{C \rho} \sum_{n=1}^{\infty} \frac{e^{-\alpha(2 / n) b^{2} a t / b^{2}}}{\left[1-\left(\alpha_{n}^{2} b^{2} /(b \sqrt{m / a})^{2}\right)\right] \alpha_{n}^{2} b^{2}} \frac{J_{1}\left(\alpha_{n} c\right) Y_{1}\left(\alpha_{n} b\right)-J_{1}\left(\alpha_{n} b\right) Y_{1}\left(\alpha_{n} c\right)}{R\left(\alpha_{n} b\right)} .
\end{aligned}
$$


The average temperature of plane A obtained by numerical model calculation is compared with the result calculated by equation (13), as shown in Figure 3. The research indicates that the average temperature of plane A obtained through the numeral model is basically consistent with the theoretical results. Therefore, the interior temperature of concrete blocks with cooling pipes can be simulated by using the numeral model based on control formula described in Section 2.1.

\section{Interior Temperature Distribution of Massive Concrete}

3.1. Parameters Setting of the Numerical Model. Three typical finite element models with the same geometric size of the concrete as shown in Figure 4 are employed to study the internal temperature distribution of mass concrete. Figure 5 shows the schematic of the interchange of heat between the annular finned cooling pipe and the concrete. Through Figure 5, it can be directly known that the surrounding annular fins of the cooling pipe play two roles: firstly, they can increase the heat transfer area between the core area of the concrete and the flowing water; secondly, as the annular fins are always metal, the heat conductivity coefficient is larger than that of concrete; therefore, the annular fins apply a fast heat exchange path.

As shown in Figures 4 and 5, the surface is mounted with fin rows with height $h_{p}$, spacing $w_{p}$, and thickness $w_{f}$. The outer diameter of the cooling pipe is D. $w_{d}$ represents the thickness of the cooling tube. The length of the cooling pipe is $l_{\mathrm{p}}$, and the length of the circumferential fins from the first piece to the last piece is $l_{f} \mathrm{O}$ denotes the geometric center of the concrete block at $(0.0,0.0,0.0) . d_{c}, h_{c}$, and $l_{c}$ shown in Figure 4 stand for the geometric dimensions of large-capacity concrete in $x, y$, and $z$ directions, respectively.

Tetrahedral elements are used to form concrete, pipes, and water flows in pipes, as shown in Figure 6(a). The highest expansion layer number of water near the pipeline is 3 , and the expansion increase rate is 1.2 , as shown in Figure 6(b). The average element mass of tetrahedral elements is above 0.8 , and the deviation value of tetrahedral elements is about 0.2 .

Thermal and geometric properties of the concrete and the pipe are given in Table 3. In Table 3, CP means the traditional cooling pipe, and AFCP stands for the annular finned cooling pipe. The velocity of inlet water is $0.6 \mathrm{~m} / \mathrm{s}$, the water influent temperature is $298 \mathrm{~K}$, and the ambient temperature is $303 \mathrm{~K}$. The heat transmission between the surrounding environment and the concrete surface is simulated through the terminal condition of heat convection, and the surface heat transmission coefficient is $3.6 \mathrm{~W} / \mathrm{m}^{2} \mathrm{~K}$.

3.2. Numerical Results. In this section, the interior temperature distributions of the concrete without cooling pipe, the concrete with traditional cooling pipe, and the concrete with annular finned cooling pipe are investigated. The cooling effect of the concrete with the traditional and the annular finned cooling pile is compared through plane A1 in
Figure 7(a). Calculation results of the temperature distribution nephogram of plane A1 for $t=1.5$ days, 2.5 days, and 3.5 days are presented in Figure 8. Through Figure 8, it can be obtained that high temperature gradient between the core area and the surface area is generated for the concrete without the cooling pipe. For the concrete with the traditional pipe and the annular finned pipe, the value of the temperature of the core area reduced. Meanwhile, comparing Figures $8(\mathrm{~b})$ and $8(\mathrm{c})$, the cooling region of the concrete embedded with the annular finned cooling pipe is larger than that with the traditional cooling pipe. Therefore, a conclusion that annular finned cooling pipe system has a better cooling efficiency than the traditional cooling pipe system can be obtained.

In order to record the temperature history of the interior area of the concrete, four points are selected in Figure 7(b). The coordinates of points $a, b, c$, and $d$ are $(0.1 \mathrm{~m}, 0.1 \mathrm{~m}$, $0.0 \mathrm{~m}),(0.2 \mathrm{~m}, 0.2 \mathrm{~m}, 0.0 \mathrm{~m}),(0.3 \mathrm{~m}, 0.3 \mathrm{~m}, 0.0 \mathrm{~m})$, and $(0.4 \mathrm{~m}$, $0.4 \mathrm{~m}, 0.0 \mathrm{~m}$ ), respectively. Temperature histories of the selected points are exhibited in Figure 9. It can be obtained from Figure 9 that the highest temperature of concrete blocks cooled by traditional cold pipe method or annular finned cold pipe method is obviously reduced. At point a, the peak temperatures of concrete without $\mathrm{CP}$, concrete containing $\mathrm{CP}$, and concrete containing $\mathrm{AFCP}$ are $337 \mathrm{~K}, 322 \mathrm{~K}$, and $309 \mathrm{~K}$, respectively. The decrease degree of concrete peak temperature with annular finned cooling pipe is greater than that with traditional cooling pipe. The occurrence time of the maximum temperature of concrete with cooling pipe is shorter than that of concrete without cooling pipes. Meanwhile, the concrete with annular finned cooling pipe reaches the maximum temperature earlier than the traditional cooling pipe. At point a, the peak temperature of $\mathrm{CP}$-free concrete, $\mathrm{CP}$-containing concrete, and AFCP-containing concrete appeared for 2.0 days, 1.5 days, and 1.0 day, respectively. The above phenomenon is more obvious in approaching the cooling pipe system. Because points $c$ and $d$ are far away from the cooling pipe system, the internal temperature decreases less than points $a$ and $b$. The temperature drop of point $d$ concrete far away from the core area of concrete is mainly due to atmospheric transmission between the surface of mass concrete and the ambient environment.

Three sections as exhibited in Figure 10 are chosen to draw the temperature distribution of concrete depth. Temperature distribution through the depth at selected sections B, C, and D are shown in Figure 11. It can be known that the temperature distribution at each section is reduced for the concrete with the cold pipe system. The temperature loss degree at section $\mathrm{B}$ is more obvious than that at sections $\mathrm{C}$ and $\mathrm{D}$ due to a reason that section $\mathrm{B}$ is closer to the cooling pipe. In addition, for concrete with annular finned cooling pipes, it can also be concluded that the cooling efficiency of internal temperature is higher than that of concrete with traditional cooling pipes.

3.3. Investigation of the Cooling Efficiency of the Annular Finned Cooling Pipe. As mentioned previously, the main property of the annular finned cooling pipe is that the heat 


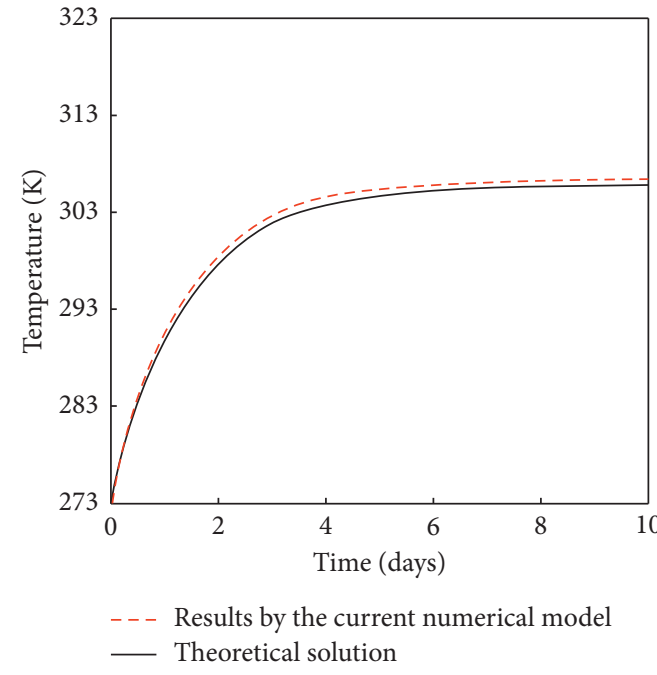

(a)

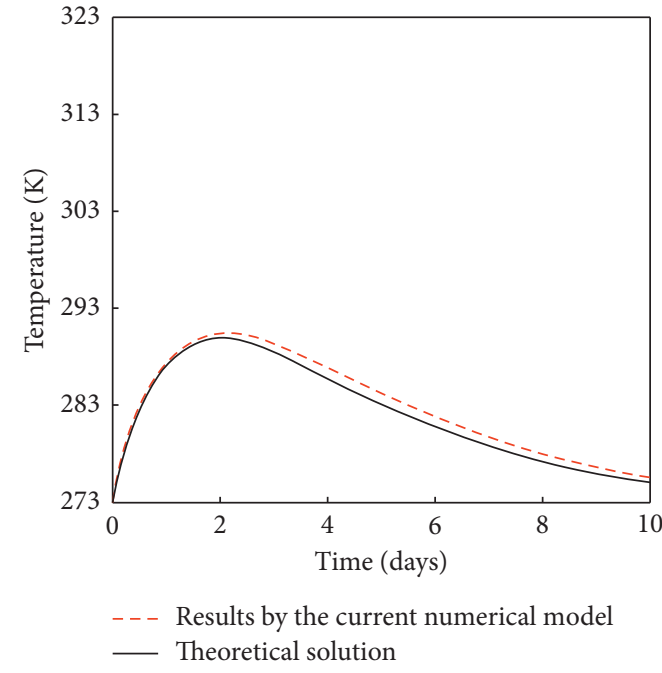

(b)

Figure 3: Temperature histories of plane A. (a) Without cooling pipe; (b) with cooling pipe.

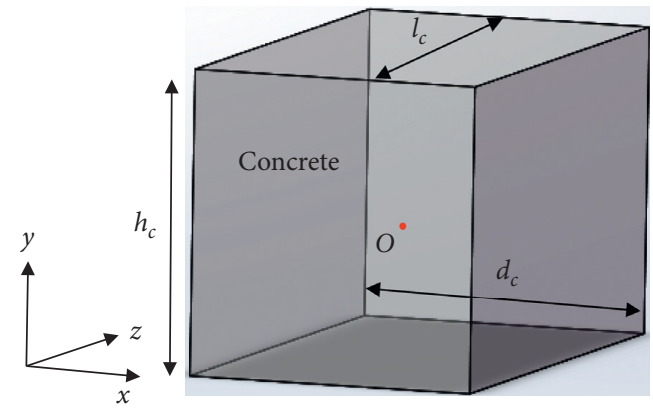

(a)

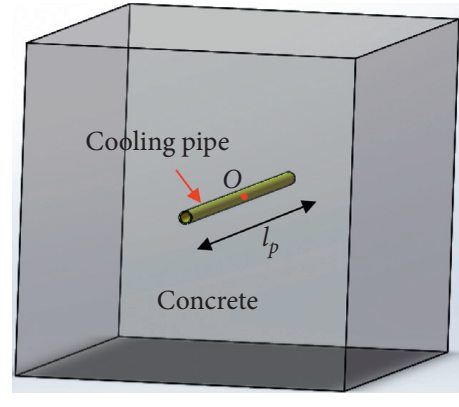

(b)

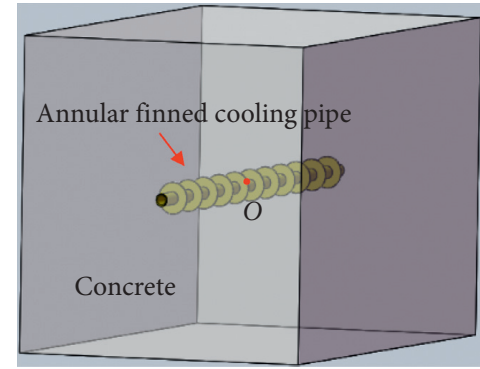

(c)

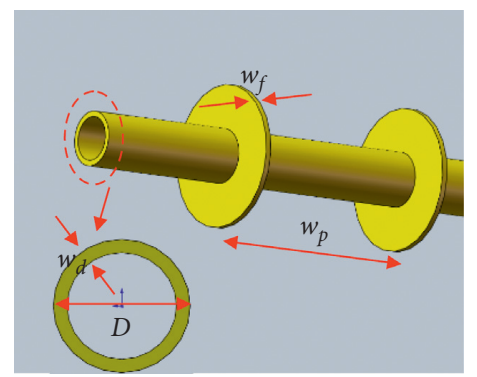

(d)

Figure 4: Diagrams of massive concrete: (a) concrete; (b) concrete with the traditional cooling pipe; (c) concrete with the annular finned cooling pipe; (d) enlarged annular finned cooling pipe.

exchange area increases compared to the traditional cooling pipe. Therefore, in this section the cooling efficiency of the annular finned cooling pipe with variation of the heat exchange area is discussed. As can be seen in Figure 5, keeping $l_{f}$ as a constant but varying the distance $w_{p}$, the heat exchange area also changes. Thus, three conditions with $w_{p}=100 \mathrm{~mm}, 200 \mathrm{~mm}$, and $400 \mathrm{~mm}$ are investigated. The calculated temperature of the selected points $a, b, c$, and $d$ is shown in Figure 12. It can be known from Figure 12 that, with decrease of the value of $w_{p}$ (which means the value of the heat transfer area increases), the cooling performance of the annular finned cooling pipe increases. Therefore, it is concluded that the surface area of the annular finned cooling pipe can dominate the internal temperature distribution of the concrete if the other parameters of the pipe are the same.

Table 4 depicts three calculation conditions. They have a common point that all the employed annular fined cooling pipes have the same heat exchange surface. Calculated temperatures of the points $a, b, c$, and $d$ are shown in Figure 13. A very interesting phenomenon can be obtained that, for the points $b, c$, and $d$ which are a little far from the pipe, the temperature histories are almost identical with each 


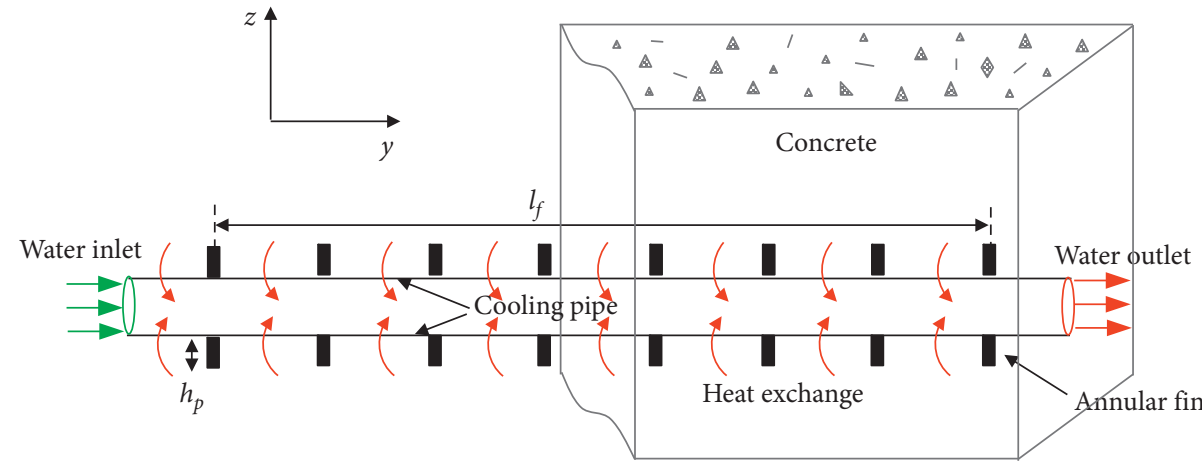

FIGURE 5: Schematics of massive concrete with the annular finned pipe in $y z$ plane.

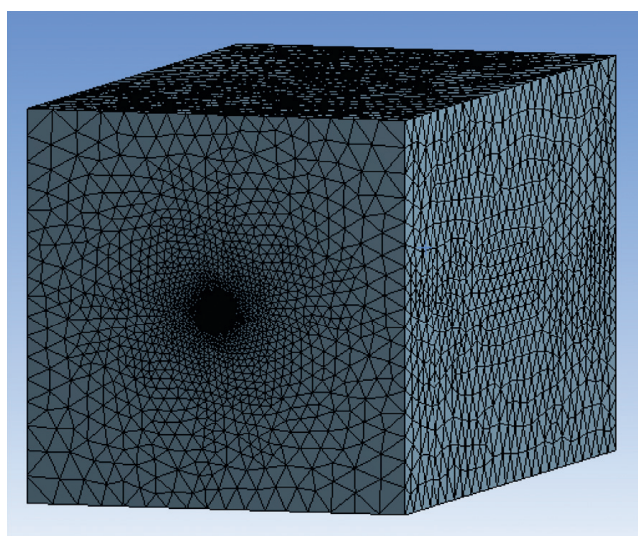

(a)

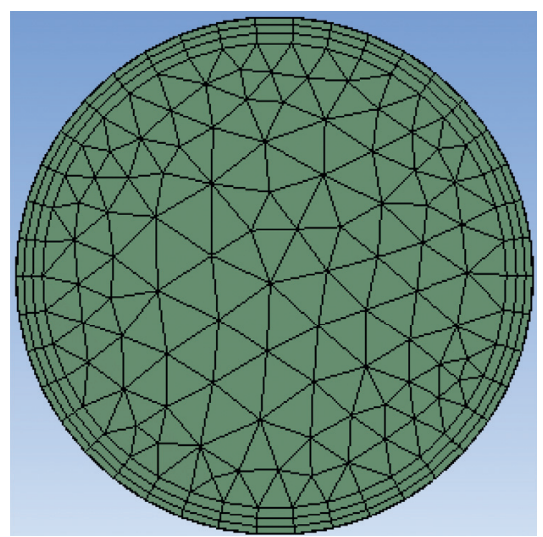

(b)

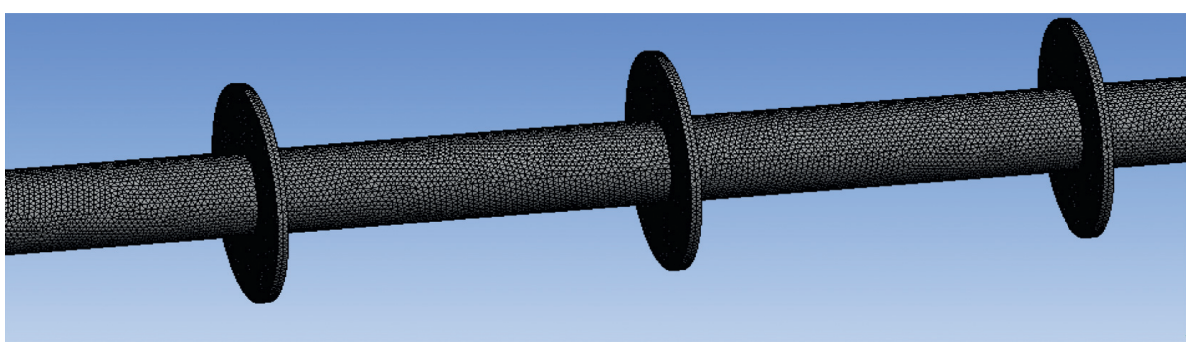

(c)

FIGURE 6: Mesh dividing of massive concrete: (a) 3D meshing; (b) water inflation setting; (c) meshing of the annular finned cooling pipe.

TABLE 3: Design geometric and thermal parameters of the concrete and pipe.

\begin{tabular}{|c|c|c|c|}
\hline Properties & Concrete & AFCP & $\mathrm{CP}$ \\
\hline Geometric sizes $(\mathrm{m})$ & $\begin{array}{l}h_{\mathrm{c}}=1.3 \\
l_{\mathrm{c}}=2.3 \\
d_{\mathrm{c}}=1.3\end{array}$ & $\begin{array}{c}D=5.0 \times 10^{-2} \\
w_{d}=5.0 \times 10^{-3} \\
w_{f}=5.0 \times 10^{-3} \\
w_{p}=1.0 \times 10^{-1} \\
l_{p}=2.3 \\
l_{f}=2.1\end{array}$ & $\begin{array}{c}D=5.0 \times 10^{-2} \\
w_{d}=5.0 \times 10^{-3} \\
l_{p}=2.3 \\
l_{f}=2.1\end{array}$ \\
\hline Adiabatic temperature $(\mathrm{K})$ & $T(t)=52.9 \times\left(1-e^{-t}\right)$ & - & - \\
\hline Specific heat $(\mathrm{J} / \mathrm{kgK})$ & 970 & 871 & 871 \\
\hline Thermal conductivity $(\mathrm{w} / \mathrm{mK})$ & 1.28 & 202.4 & 202.4 \\
\hline
\end{tabular}

other. However, for point a, the temperature histories of AF_200_100, AF_100_66.4, and AF_400_143.6 have obvious differences. The reason is that, for the point $a$, which is near the cooling pipe, the temperature of the point is not only dominated by the surfaces area of the annular finned cooling pipe, but also controlled by the distance between the point and the adjacent annular fins. For the mental annular fins, they have a higher heat conductivity coefficient than the 


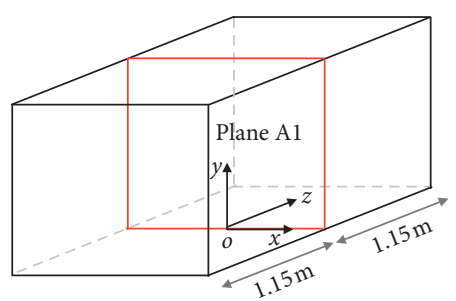

(a)

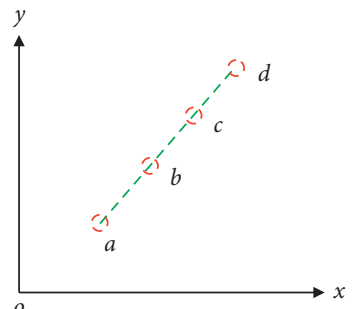

(b)

FIGURE 7: Diagrams of selected plane and points: (a) selected plane; (b) selected points.
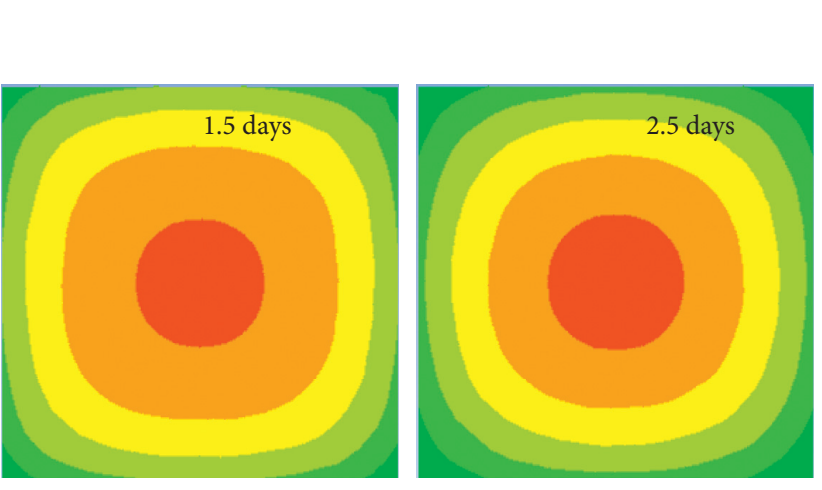

(a)
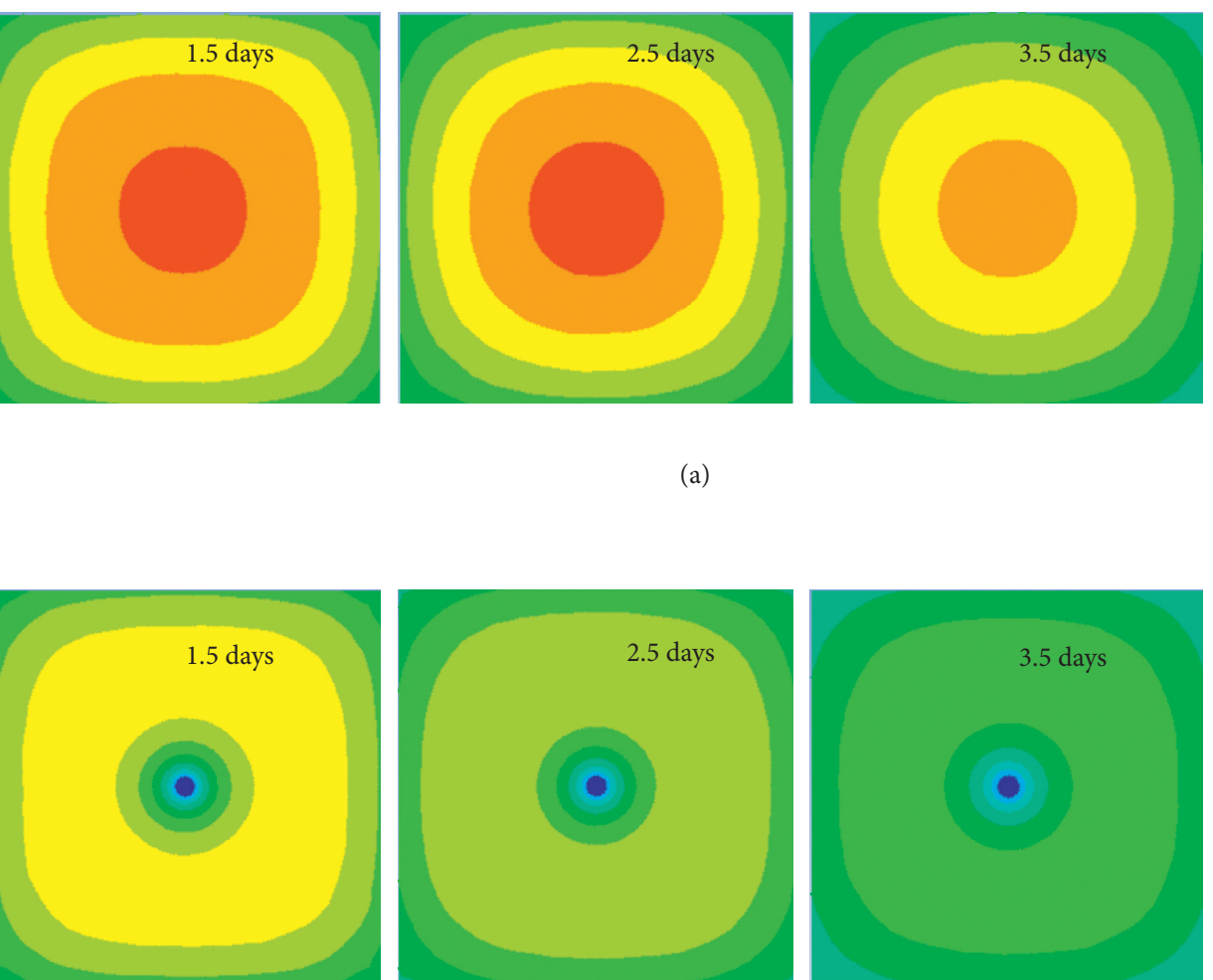

Temperature

contour plan A

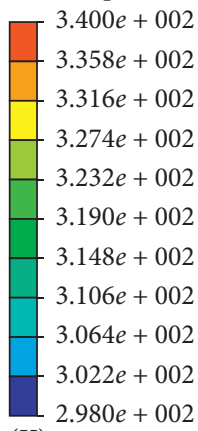

(K)

Temperature contour plan A

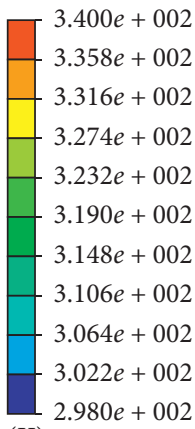

(K)

(b)

\section{Temperature}

contour plan A
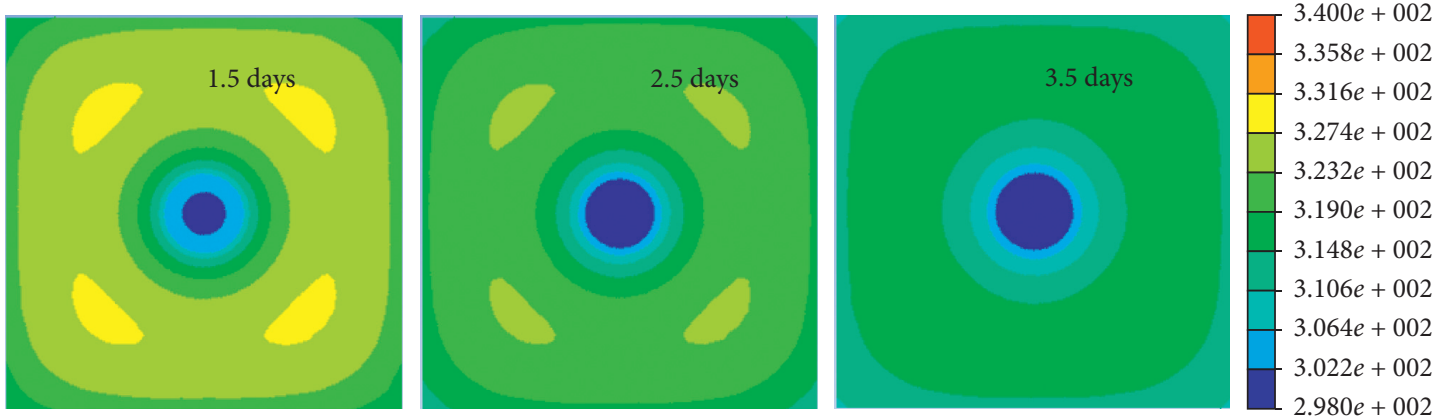

(K)

(c)

FIgure 8: Temperature distributions of plane A1: (a) concrete without CP; (b) concrete with CP; (c) concrete with AFCP. 

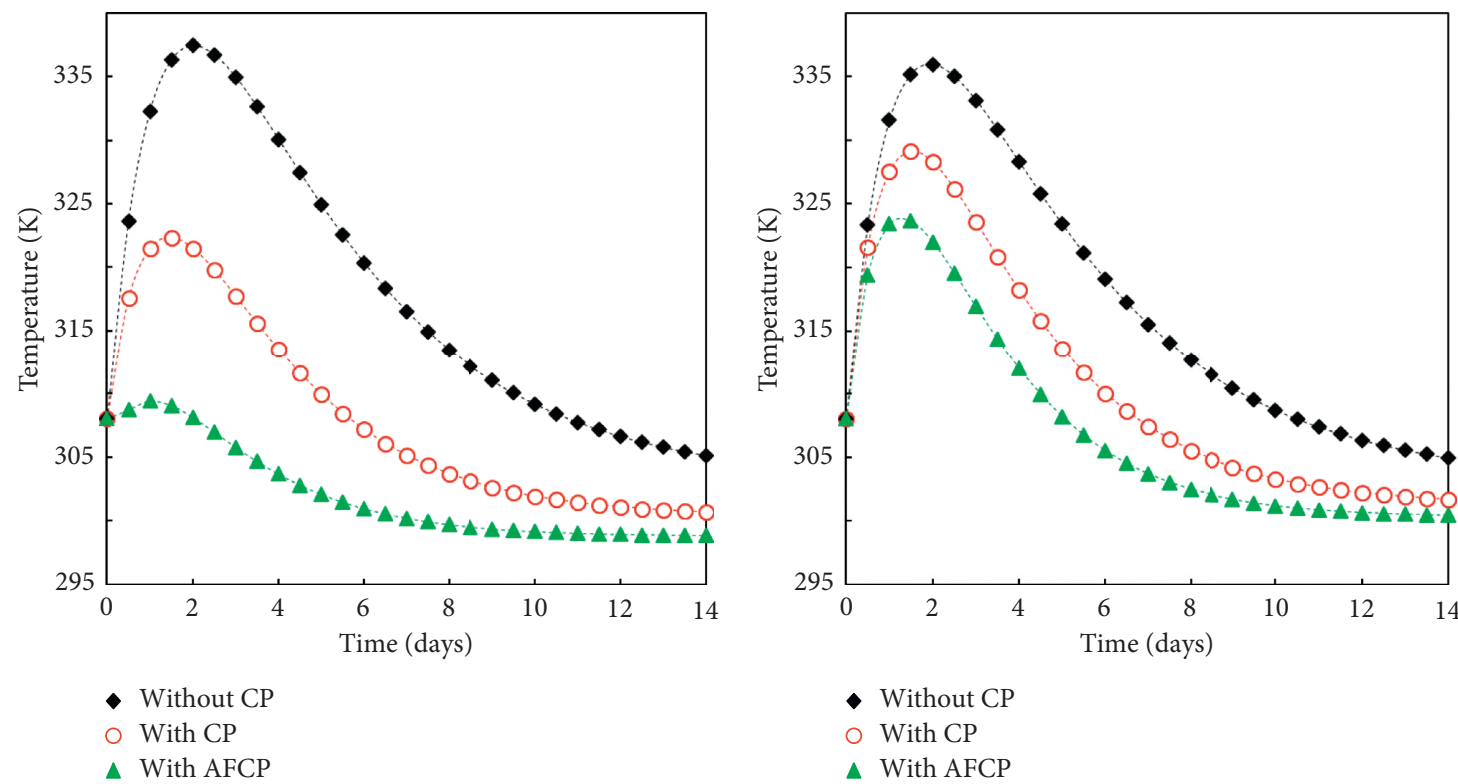

(a)

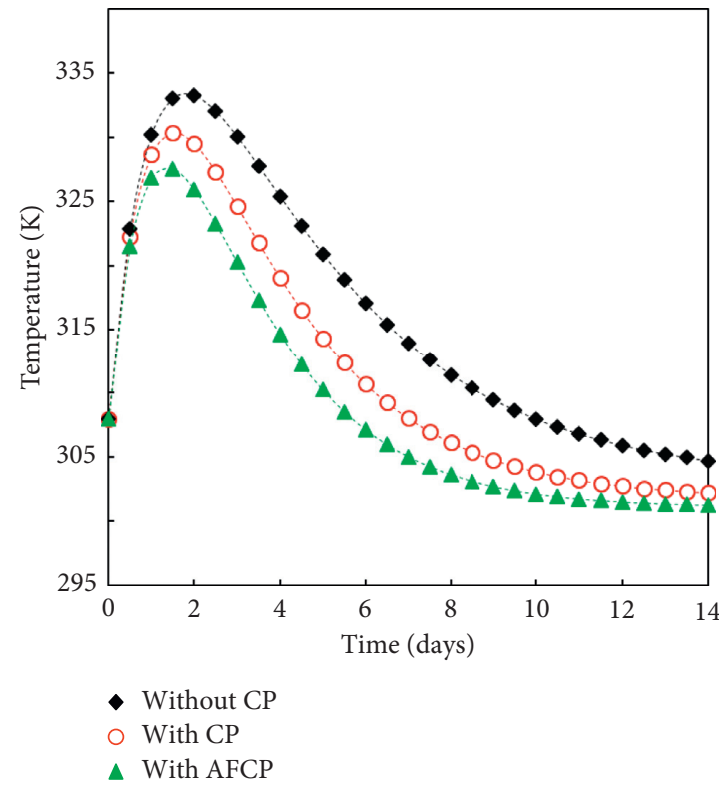

(c)

(b)

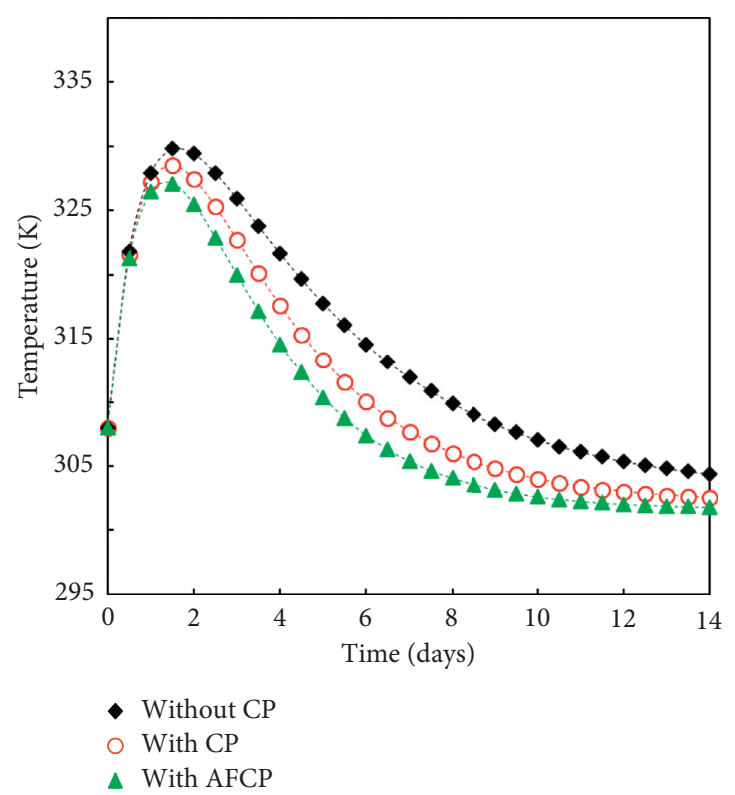

(d)

Figure 9: Temperature histories of the selected points: (a) point $a$; (b) point $b$; (c) point $c$; (d) point $d$.

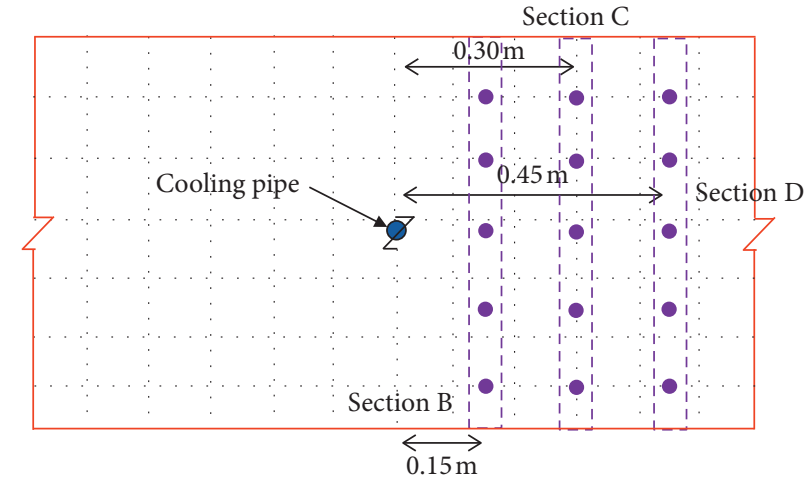

Figure 10: Selected sections of plane A1. 


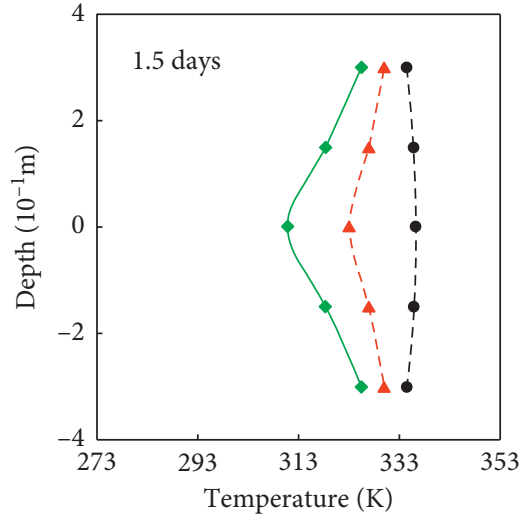

- Without CP

$\Delta$ With $\mathrm{CP}$

- With AFCP

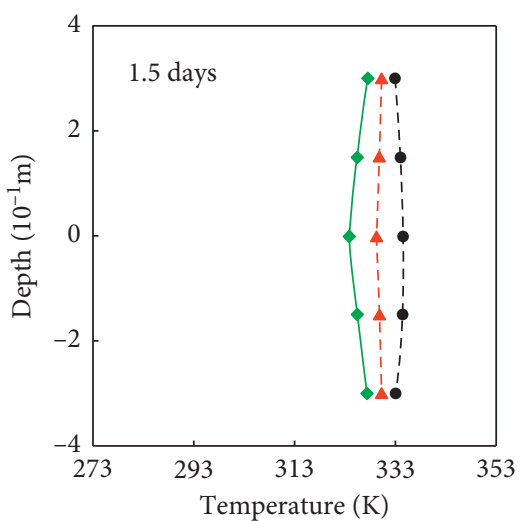

- Without CP

- With $\mathrm{CP}$

- With AFCP

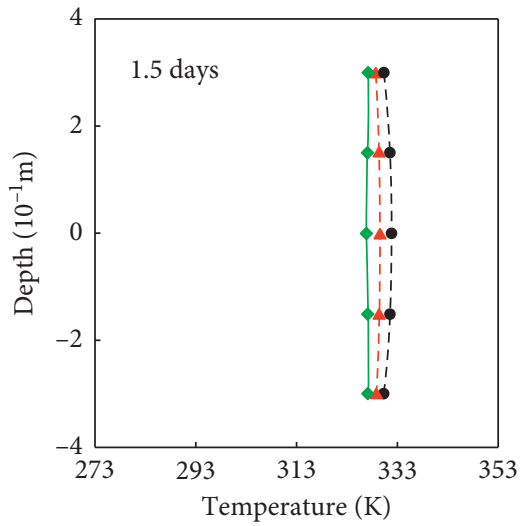

- Without CP

- With CP

- With AFCP

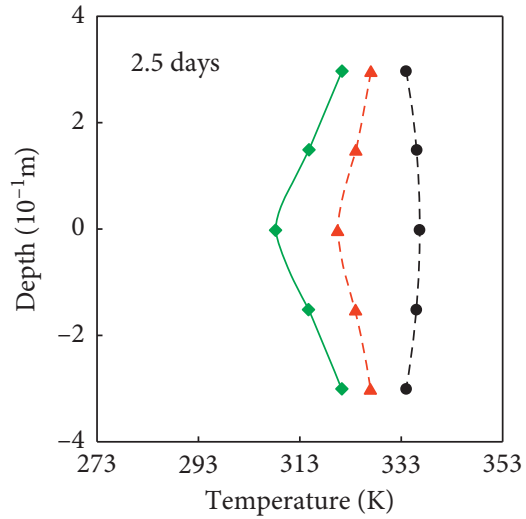

- Without CP

- With CP

- With AFCP

(a)

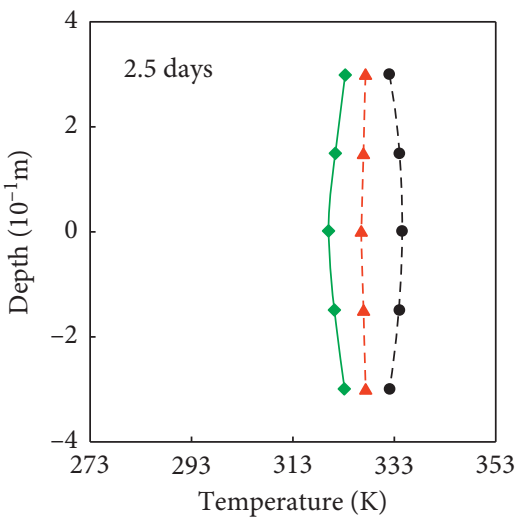

- Without CP

- With $\mathrm{CP}$

- With AFCP

(b)

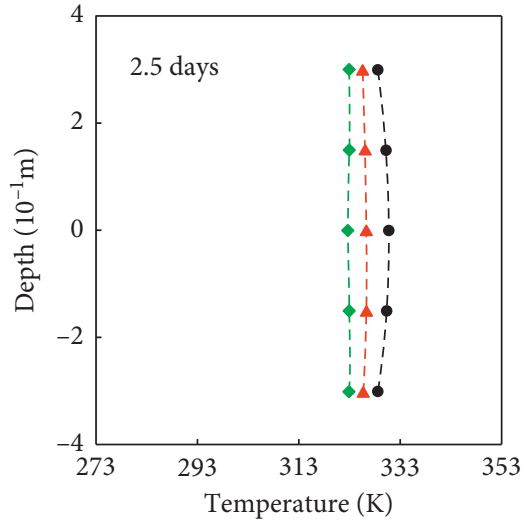

- Without CP

- With CP

- With AFCP

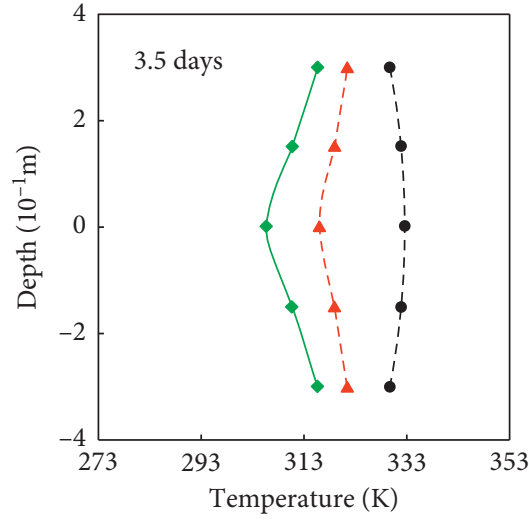

- Without CP

a With CP

- With AFCP

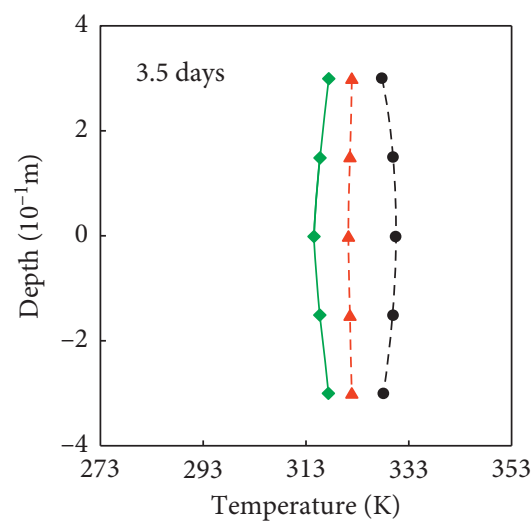

- Without CP

$\Delta$ With $\mathrm{CP}$

- With AFCP

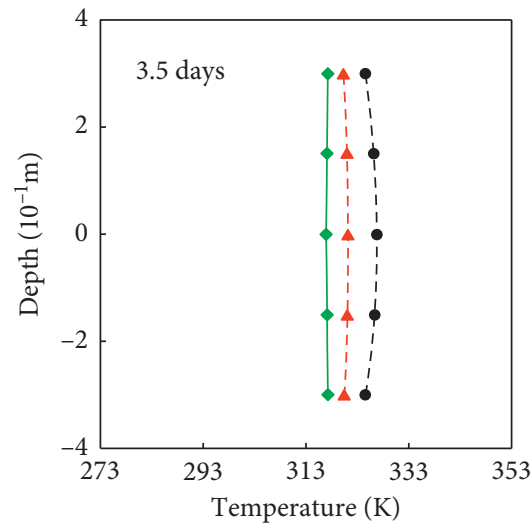

- Without CP

- With CP

- With AFCP

(c)

Figure 11: Temperature distribution of concrete at (a) section $\mathrm{B}$, (b) section $\mathrm{C}$, and (c) section D. 


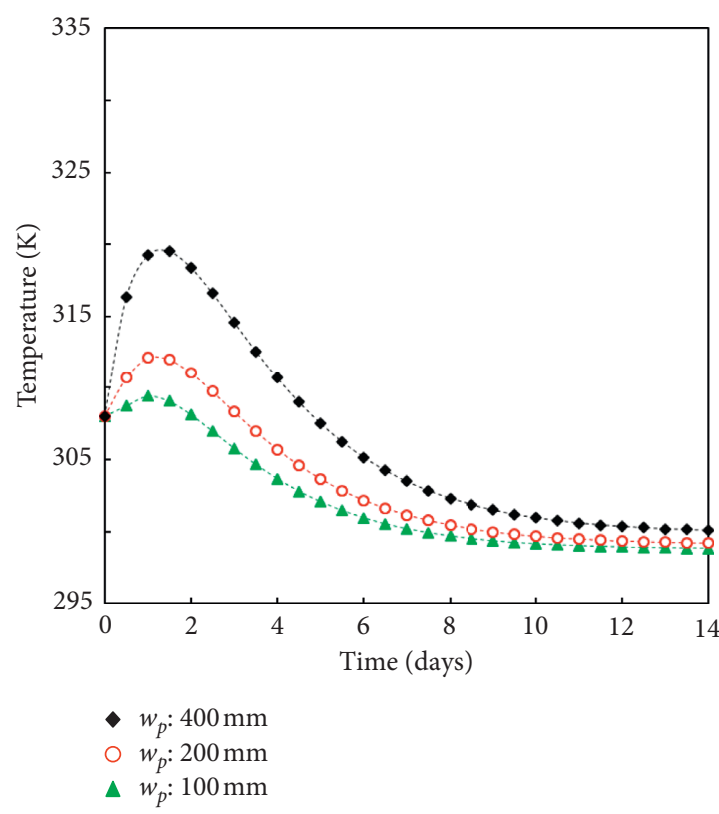

(a)

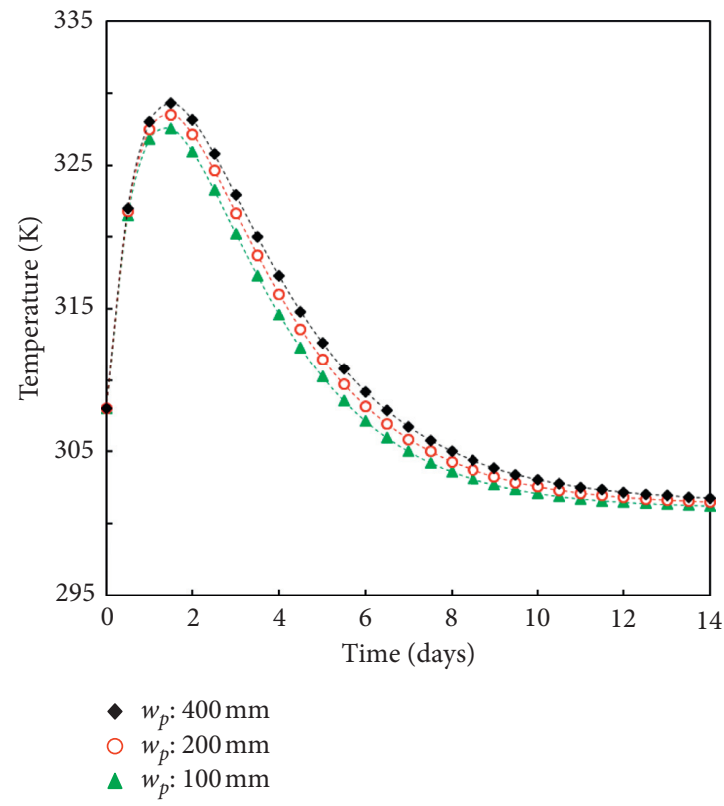

(c)

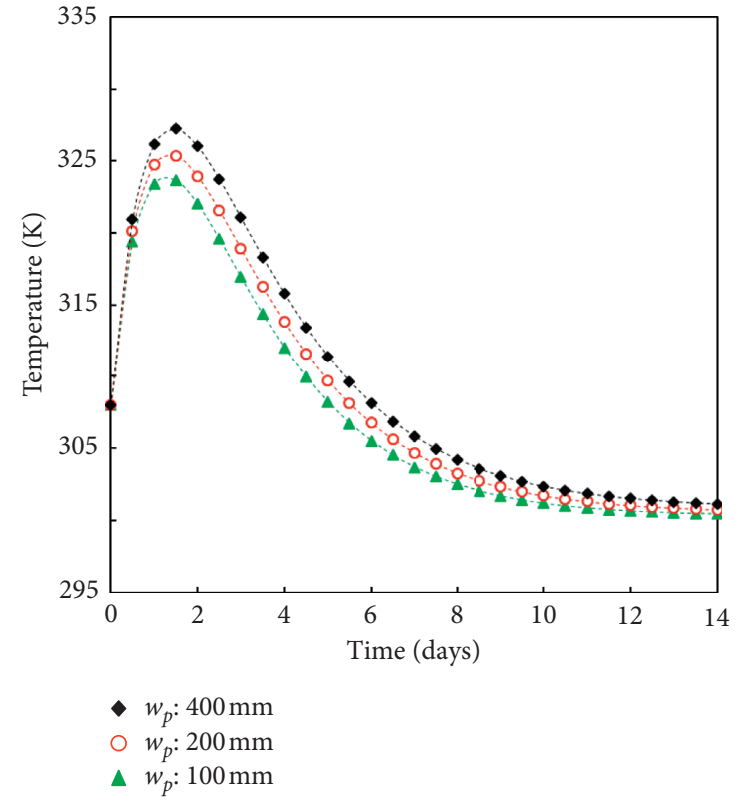

(b)

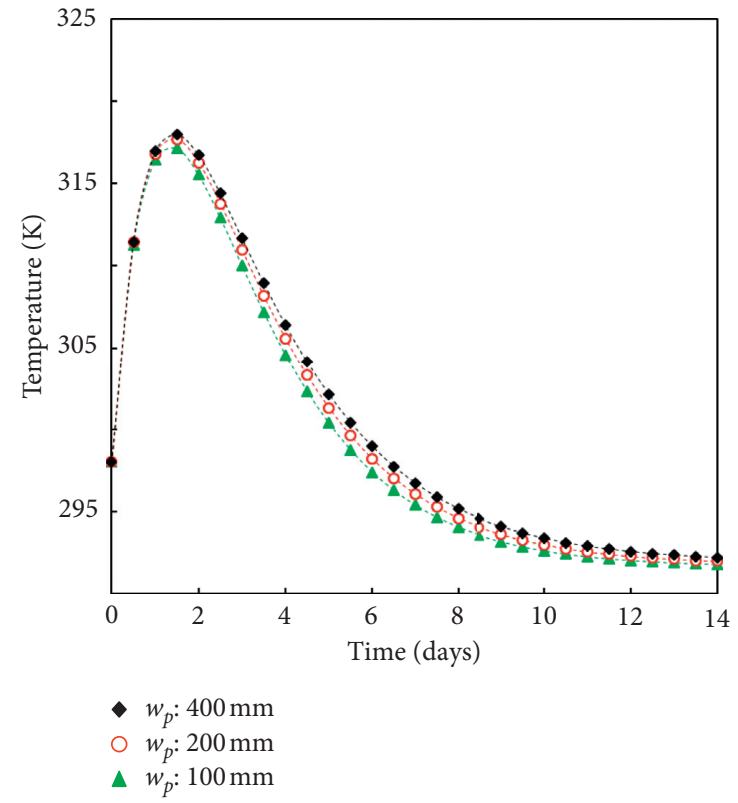

(d)

Figure 12: Temperature histories of the points with variation of $w_{p}$ : (a) point $a$; (b) point $b$; (c) point $c$; (d) point $d$.

concrete; thus the points which are adjacent to the annular fins have shorter heat transfer path. Calculation results of the temperature distribution nephogram of plane A1 for 2.5 days are shown in Figure 14. Through Figure 14, it can be obtained that, for the area near to the cooling pipe, the temperature distributions of AF_200_100, AF_100_66.4, and AF_400_143.6 have some differences. Moreover, for the area a little far from the pipe, the temperature distribution is almost the same. Therefore, what we can say is that the surface area and the distance between the point and the annular fins are the two key factors which control the temperature distribution of the concrete. 
TABLE 4: Annular finned cooling pipe with the same surface area.

\begin{tabular}{lccc}
\hline Case name & $w_{p}(\mathrm{~mm})$ & $h_{p}(\mathrm{~mm})$ & Surface $\operatorname{area}^{\left(\mathrm{mm}^{2}\right)}$ \\
\hline AF_200_100 & 200 & 100 & $1.43 \times 10^{6}$ \\
AF_100_66.4 & 100 & 66.4 & $1.43 \times 10^{6}$ \\
AF_400_143.6 & 400 & 143.6 & $1.43 \times 10^{6}$ \\
\hline
\end{tabular}
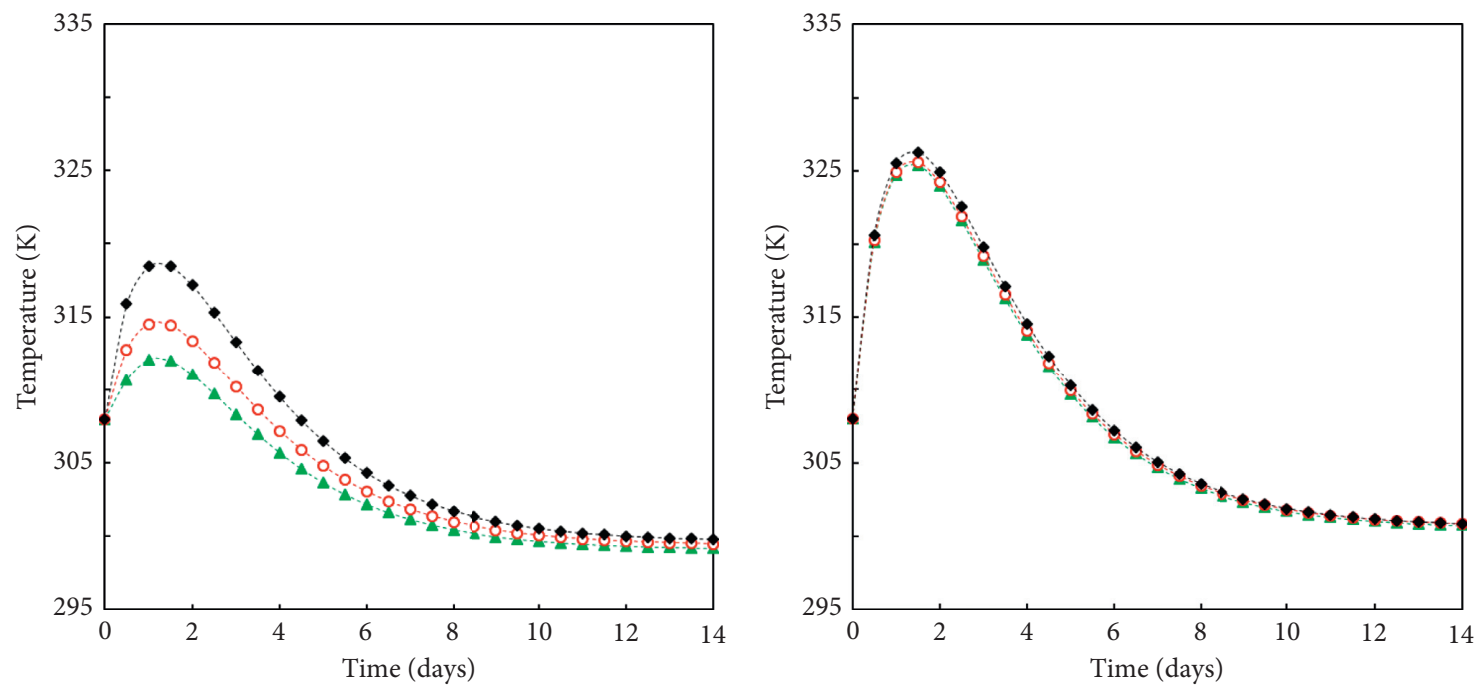

- AF_400_143.6

- AF_400_143.6

○ AF_100_66.4

○ AF_100_66.4

A AF_200_100

A AF_200_100

(a)

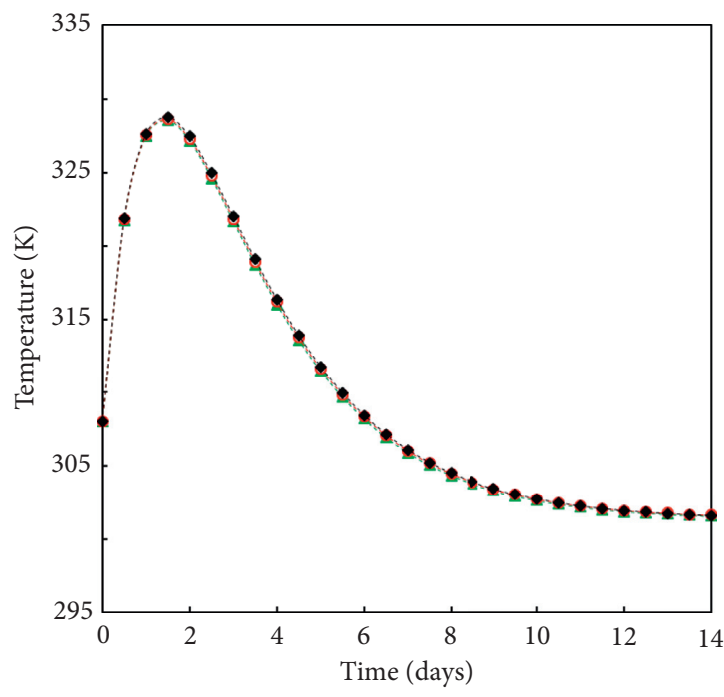

(b)

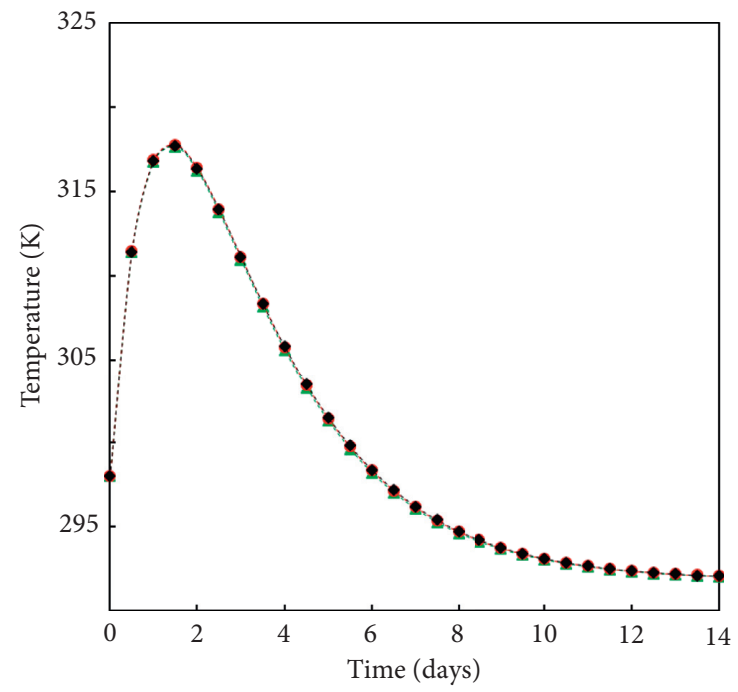

- AF_400_143.6

- AF_400_143.6

○ AF_100_66.4

O AF_100_66.4

\ AF_200_100

(c)

(d)

Figure 13: Temperature histories of the points with the same heat exchange area of the annular finned cooling pipe: (a) point $a$; (b) point $b$; (c) point $c$; (d) point $d$. 


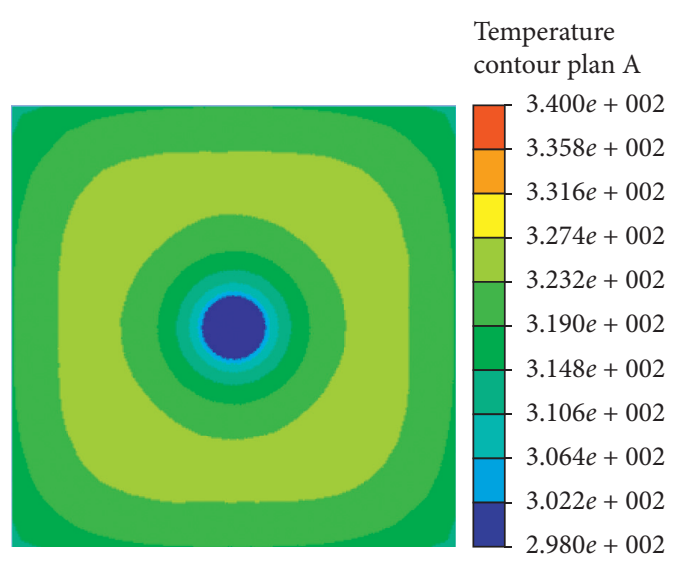

(K)

(a)

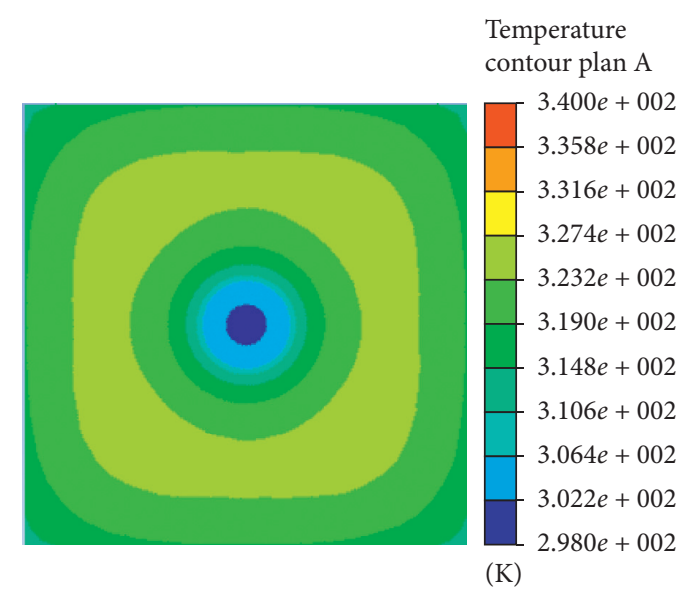

(b)
Temperature contour plan A

Temperature contour plan A

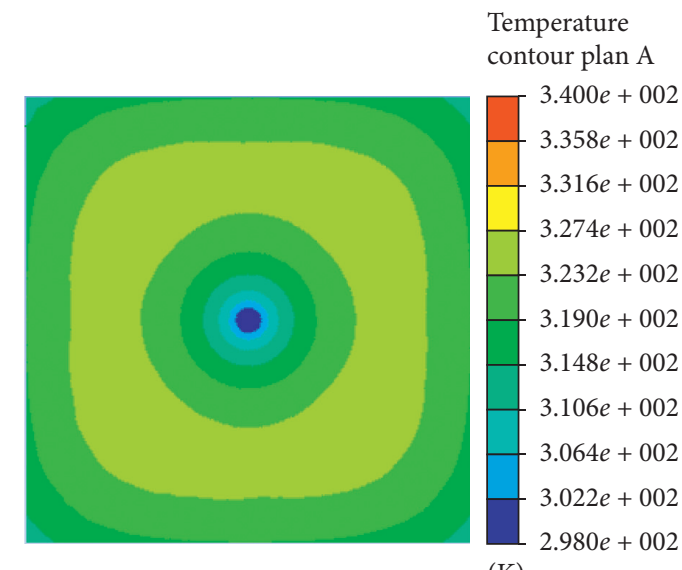

(K)

(c)

Figure 14: Temperature distributions of plane A at 2.5 days: (a) AF_100_66.4; (b) AF_200_100; (c) AF_400_143.6.

\section{Conclusions}

A novel annular fin cooling pipe for reducing the internal temperature of mass concrete is proposed. A 3D finite element model is employed to study the temperature distribution of massive concrete cooling pipes with annular finned and traditional cooling pipes. The results lead to the following conclusions:

(1) Concrete with traditional cooling pipes or annular finned cooling pipes can reduce the temperature in the core area. However, compared with traditional cooling pipes, the cooling range of annular finned cooling tubes is wider. Thus, the annular finned cooling pipe system has a better cooling efficiency than the traditional cooling pipe system.

(2) For concrete embedded with traditional cooling pipes or annular finned cooling pipes, the peak temperature can be reduced. However, comparing the traditional cooling pipe, the peak temperature of concrete in the annular finned cooling pipe decreases more. The concrete with annular finned cooling pipe has the highest temperature earlier than the traditional cooling pipe.
(3) At points near the cooling pipe system, the temperature drops more than at points away from the cooling pipe system. Under the condition of constant inlet velocity and inlet temperature, the surface area of the cooling pipe and the distance between the cooling pipe and the annular finned are two important factors to control the temperature distribution of concrete.

\section{Data Availability}

The data used to support the findings of this study are available from the corresponding author upon request.

\section{Conflicts of Interest}

The authors declare that they have no conflicts of interest.

\section{Acknowledgments}

The authors gratefully acknowledge the financial support for this research provided by the National Key Research and Development Plan of China (Grant no. 2017YFC1500705) 
and the National Natural Science Foundation of China (Grant nos. 51878314 and 51308243).

\section{References}

[1] A. Bakour and M. B. Ftima, "Experimental investigations on the asymptotic fracture energy for large mass concrete specimens using wedge splitting test," Construction and Building Materials, vol. 279, Article ID 122405, 2021.

[2] B. M. Luccioni, M. I. Figueroa, and R. F. Danesi, "Thermomechanic model for concrete exposed to elevated temperatures," Engineering Structures, vol. 25, no. 6, pp. 729-742, 2003.

[3] B. Luccioni, F. Isla, R. Codina et al., "Experimental and numerical analysis of blast response of high strength fiber reinforced concrete slabs," Engineering Structures, vol. 175, pp. 113-122, 2018.

[4] W. Lin, F. Zhou, W. Luo, and L. Yuo, "Recycling the waste dolomite powder with excellent consolidation properties: sample synthesis, mechanical evaluation, and consolidation mechanism analysis," Construction and Building Materials, vol. 290, Article ID 123198, 2021.

[5] K. Liu, H. Xie, P. Xu, Z. Wang, H. Bai, and F. Wang, "The thermal and damage characteristics of an insulated-conductive composite structure for the heated bridge deck for snowmelting," Construction and Building Materials, vol. 216, pp. 176-187, 2019.

[6] K. Liu, P. Xu, F. Wang et al., "The accumulated stress damage and residual life prediction of unreinforced concrete pavement with electric heating pipes," Construction and Building Materials, vol. 278, no. 5-6, Article ID 122258, 2021.

[7] Aci, ACI 207.4r-05: Cooling and Insulating System for Mass concrete, American Concrete Institute, Farmington Hills, MI, USA, 2005.

[8] U.S. Department of the Interior and Bureau of Reclamation, “Temperature Control of Concrete," Design of Gravity Dam, pp. 107-136, A water Resources Technical Publication, Denver, CO, US, 1976.

[9] E. Mead, "Research work of the Bureau of reclamation," Scientific Monthly, vol. 36, no. 4, pp. 295-307, 1933.

[10] B. Zhu and J. Cai, "Finite element analysis of effect of pipe cooling in concrete dams," Journal of Construction Engineering and Management, vol. 115, no. 4, pp. 487-498, 1989.

[11] J. Ding and S. Chen, "Simulation and feedback analysis of the temperature field in massive concrete structures containing cooling pipes," Applied thermal Engineering, vol. 61, pp. 554-562, 2013.

[12] R. Zhong, G.-p. Hou, and Q. Sheng, "An improved composite element method for the simulation of temperature field in massive concrete with embedded cooling pipe," Applied thermal Engineering, vol. 124, pp. 1409-1417, 2017.

[13] G. Chen, X. Ding, M. Cai, and W. Qiao, “Analytical solution for temperature field of nonmetal cooling pipe embedded in mass concrete," Applied Thermal Engineering, vol. 158, Article ID 113774, 2019.

[14] A. R. Mogharrebi, A. R. D. Ganji, and K. Hosseinzadeh, "Investigation of magnetohydrodynamic nanofluid flow contain motile oxytactic microorganisms over rotating cone," International Journal of Numerical Methods for Heat \& Fluid Flow, 2020.

[15] J. K. Kim, K. H. Kim, and J. K. Yang, "Thermal analysis of hydration heat in concrete structures with pipe-cooling system," Computers and Structures, vol. 79, pp. 163-171, 2001.
[16] T. G. Myers, N. D. Fowkes, and Y. Ballim, "Modeling the cooling of concrete by piped water," J. Eng. Mech.vol. 135, no. 12, pp. 1375-1383, 2009.

[17] J. Yang, Y. Hu, Z. Zheng, F. Feng, and L. Qingbin, “Thermal analysis of mass concrete embedded with double-layer staggered heterogeneous cooling water pipes," Applied thermal Engineering, vol. 35, pp. 145-156, 2012.

[18] X. Liu, C. Zhang, X. Chang, W. Zhou, Y. Cheng, and Y. Duan, "Precise simulation analysis of the thermal field in mass concrete with a pipe water cooling system," Applied Thermal Engineering, vol. 78, pp. 449-459, 2015.

[19] Y.-X. Hong, C. Wen, J. Lin, J. Gong, and H.-d. Cheng, "Thermal field in water pipe cooling concrete hydro-structures simulated with singular boundary method," Water Science and Engineering, vol. 10, no. 2, pp. 107-114, 2017.

[20] A. K. Rostami, Kh Hosseinzadeh, and D. D. Ganji, "Hydrothermal analysis of ethylene glycol nanofluid in a porous enclosure with complex snowflake shaped inner wall," Waves in Random and Complex Media, 2020.

[21] C. Qian and G. Gao, "Reduction of interior temperature of mass concrete using suspension of phase change materials as cooling fluid," Construction and Building Materials, vol. 26, pp. 527-531, 2012.

[22] X. Liu, Y. Duan, W. Zhou, and X. Chang, "Modeling the piped water cooling of a concrete dam using the heat-fluid coupling method," Journal of Engineering Mechanics, vol. 139, no. 9, pp. 1278-1289, 2013.

[23] Y. Huang, G. Liu, S. Huang, R. Rao, and C. Hu, "Experimental and finite element investigations on the temperature field of a massive bridge pier caused by the hydration heat of concrete," Construction and Building Materials, vol. 192, pp. 240-252, 2018.

[24] M. Wu, Y. Zhang, Y. Jia et al., "Influence of sodium hydroxide on the performance and hydration of lime-based low carbon cementitious materials," Construction and Building Materials, vol. 20, pp. 604-615, 2019.

[25] Y. Geng, X. Li, S. Xue, J. Li, and Y. Song, "Experimental and theoretical internal forced convection investigation on air pipe cooling of large-dimension RC walls," Construction and Building Materials, vol. 194, pp. 161-170, 2019.

[26] Y. Hong, J. Lin, and C. Wen, "Simulation of thermal field in mass concrete structures with cooling pipes by the localized radial basis function collocation method," International Journal of Heat and Mass Transfer, vol. 129, pp. 449-459, 2019.

[27] Kh Hosseinzadeh, S. Roghani, A. R. Mogharrebi, A. Asadi, and D. D. Ganji, "Optimization of hybrid nanoparticles with mixture fluid flow in an octagonal porous medium by effect of radiation and magnetic field," Journal of Thermal Analysis and Calorimetry, 2020.

[28] Mohurd, Ministry of Housing and Urban-Rural Development of the People's Republic of China, Standard for construction of mass concrete, State Administration for Market Regulation, Beijing, China, 2018.

[29] B. F. Zhu, "Effect of cooling by water flowing in nonmetal pipes embedded in massive concrete," J. Constr. Eng. Manage, vol. 125, no. 1, pp. 61-68, 1999.

[30] B. Zhu, Thermal Stresses and Temperature Control of Mass Concrete, Tsinghua University Press, Beijing, China, 2012. 